\title{
Temperature fiber-optic sensor with ZnO ALD coating ${ }^{\dagger}$
}

\author{
Paulina Listewnik ${ }^{1, *}$ \\ 1 Department of Metrology and Optoelectronics, Faculty of Electronics, Telecommunications and \\ Informatics, Gdańsk University of Technology, 11/12 Narutowicza Street, 80-233 Gdańsk, Poland \\ * Correspondence: pauliste@student.pg.edu.pl; (P.L.) \\ + Presented at the 7th Electronic Conference on Sensors and Applications, 15-30 November 2020; Available \\ online: https://ecsa-7.sciforum.net/.
}

Received: date; Accepted: date; Published: date

\begin{abstract}
This study presents of the microsphere-based fiber-optic sensor with the ZnO ALD coating thickness of $100 \mathrm{~nm}$ for temperature measurements. Metrological properties of the sensor were investigated over the temperature range of $100^{\circ} \mathrm{C}$ to $300^{\circ} \mathrm{C}$, with a $10^{\circ} \mathrm{C}$ step. Interferometric signal is used to control whether the microstructure is whole. Spectrum shift of a reflected signal is used to conclude changes in measured parameter. With changing temperature, the peak position of a reflected signal also changes. The $\mathrm{R}^{2}$ coefficient of presented sensor indicates a good linear fit of over 0.99 to the obtained data. Sensitivity of the sensor, investigated in this study, equals $0.019 \mathrm{~nm} /{ }^{\circ} \mathrm{C}$.
\end{abstract}

Keywords: atomic layer deposition; fiber-optic; microsphere; temperature; $\mathrm{ZnO}$

\section{Introduction}

Fiber-optic sensors have been developed and improved upon for over a decade. Due to their versatility, they are used in numerous fields, such as industry, science or medicine [1-4]. Optimization of measurement parameters plays a significant role in development of the fiber-optic sensors. While planning measurements, selection of the sensor is crucial element, depending on their purpose and conditions, in which they will be performed. Based on the type of sensor, diversity of designs and parameters can be optimized: adjustable cavity length, structure modification [5-8], as well as metrological properties, such as: resolution, precision, sensitivity, accuracy $[9,10]$. Many researchers contribute to determine properties and parameters of various materials and structures $[11,12]$.

This study investigates sensing abilities of the microsphere-based fiber-optic sensor with a $100 \mathrm{~nm} \mathrm{ZnO}$ ALD coating during temperature measurements.

\section{Materials and Methods}

Measurements were performed using a sensor made of a standard single-mode telecommunication optical fiber (SMF-28, Thorlabs Inc., Newton, NJ, USA) with a microsphere structure produced at the end of the fiber, using fiber-optic splicer (FSU975, Ericsson, Sweden). Obtained microsphere has diameter of $245 \mu \mathrm{m}$. After the manufacturing of the microsphere, the $\mathrm{ZnO}$ coating of $100 \mathrm{~nm}$ thickness was deposited on its surface by Atomic Layer Deposition (ALD) method. Detailed description of the deposition process is presented elsewhere [13,14].

To assess quality of the structure and the deposited ZnO ALD coating of $100 \mathrm{~nm}$ thickness, it was then investigated under Scanning Electron Microscope (SEM, Phenom XL G2, Thermo Fisher Scientific, Waltham, MA, USA), which results are shown in Figure 1. 


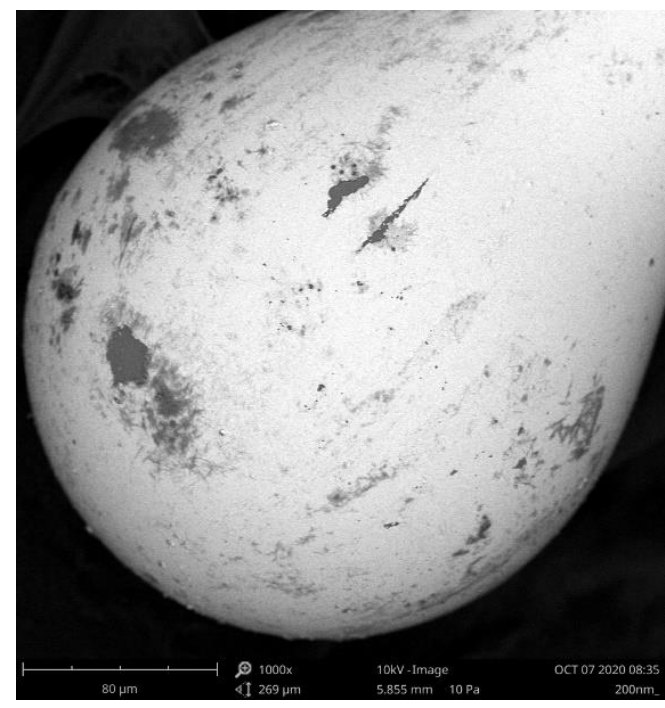

Figure 1. SEM image of the microsphere-sensor with a $100 \mathrm{~nm} \mathrm{ZnO}$ ALD coating. Magnification of $1000 x$

The image shows the device with a magnification of $1000 \mathrm{x}$ and it can be seen, the structure exhibit excellent roundness. Furthermore, the presence of $\mathrm{ZnO}$ coating is apparent.

Moreover, metrological properties of the sensor were validated by performing experimental measurements. During investigation, sensor is placed in temperature calibrator (ETC-400A, Ametek, Berwyn, PA, USA), which was increased from $100^{\circ} \mathrm{C}$ to $300^{\circ} \mathrm{C}$, with a $10^{\circ} \mathrm{C}$ step. Temperature was stabilized for 3 minutes, at each step, allowing the sensor to adjust to altered conditions. The measurements were executed using a light source with a center wavelength of $1310 \mathrm{~nm} \pm 20 \mathrm{~nm}$ (SLD1310-18-W, FiberLabs Inc., Fujimino, Japan). The signal was propagated through a 2:1 50/50\% optical coupler (G657A, CELLCO, Kobylanka, Poland) to the sensor head coated with a $100 \mathrm{~nm}$ ZnO ALD coating, which is highly reflective, allowing the wave to superpose, therefore inciting interference as shown in Figure 2.

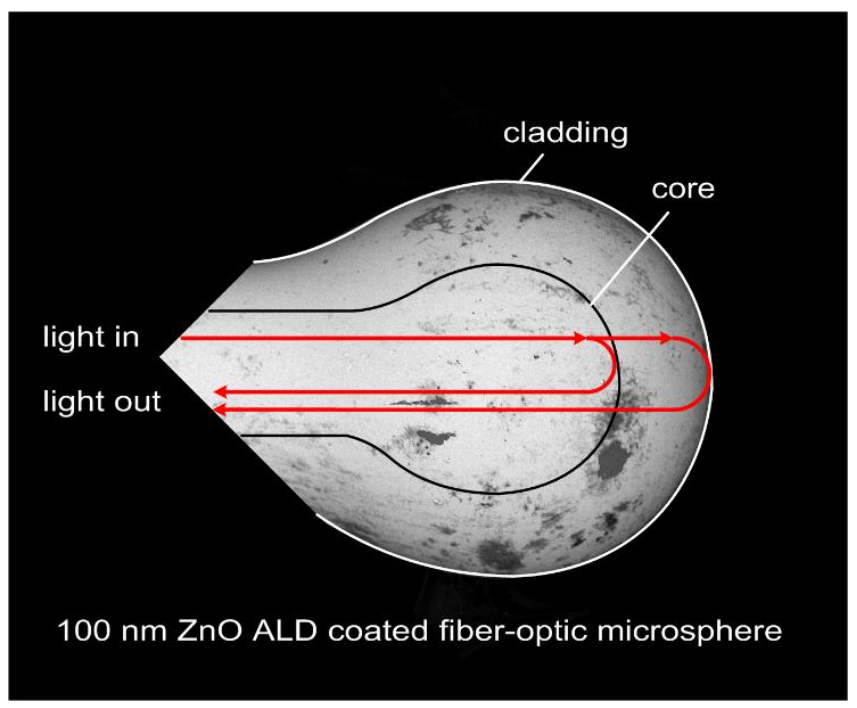

Figure 2. Principle of operation of a microsphere-based fiber-optic sensor.

By obtaining interference, the integrity of the structure can be monitored, ensuring the sensor is not damaged. Reflected signal is then collected by Optical Spectrum Analyzer (OSA, Ando AQ6319, Yokohama, Japan). Depending on the position of the spectral peak of the signal, temperature can be determined.

\section{Results and Discussion}


This section presents results, which were acquired from the measurements performed with the setup shown above.

Figure 3 shows normalized values of the measured signal response for the microsphere-based sensor with a $100 \mathrm{~nm} \mathrm{ZnO} \mathrm{ALD} \mathrm{coating,} \mathrm{at} 100^{\circ} \mathrm{C}$ and $300^{\circ} \mathrm{C}$ to preserve readability of the plot. By rising the temperature, spectral peak of the reflected signal shifts toward lower values of the wavelength. The envelope, however, remains the similar for each temperature. In addition, interference fringes visible in the Figure, inform about the integrity of the sensor head structure, which allows to monitor its condition in real-time.

a)

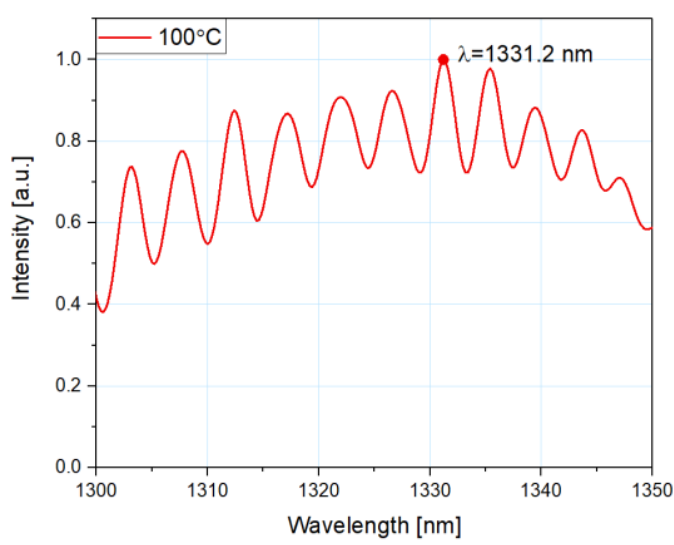

b)

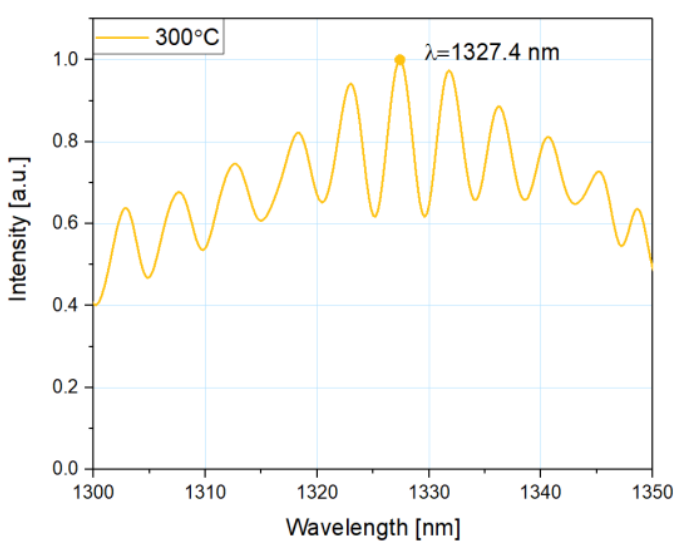

Figure 3. Normalized measured response of the reflected signal for the microsphere-based sensor with $100 \mathrm{~nm} \mathrm{ZnO} \mathrm{ALD} \mathrm{coating} \mathrm{at:} \mathrm{a)} 100^{\circ} \mathrm{C}$ and b) $300^{\circ} \mathrm{C}$.

Dependence of the peak wavelength position on the temperature can be observed in Figure 4 . Moreover, theoretical linear fit is also presented, as well as coefficient $\mathrm{R}^{2}$, which equals 0.99176 , was determined to confirm fitness of the obtained data to the theoretical model. Furthermore, the results presented in Figure 4 allowed to calculate the sensitivity of the microsphere-based sensor with a 100 $\mathrm{nm} \mathrm{ZnO}$ ALD coating $-0.019 \mathrm{~nm} /{ }^{\circ} \mathrm{C}$.

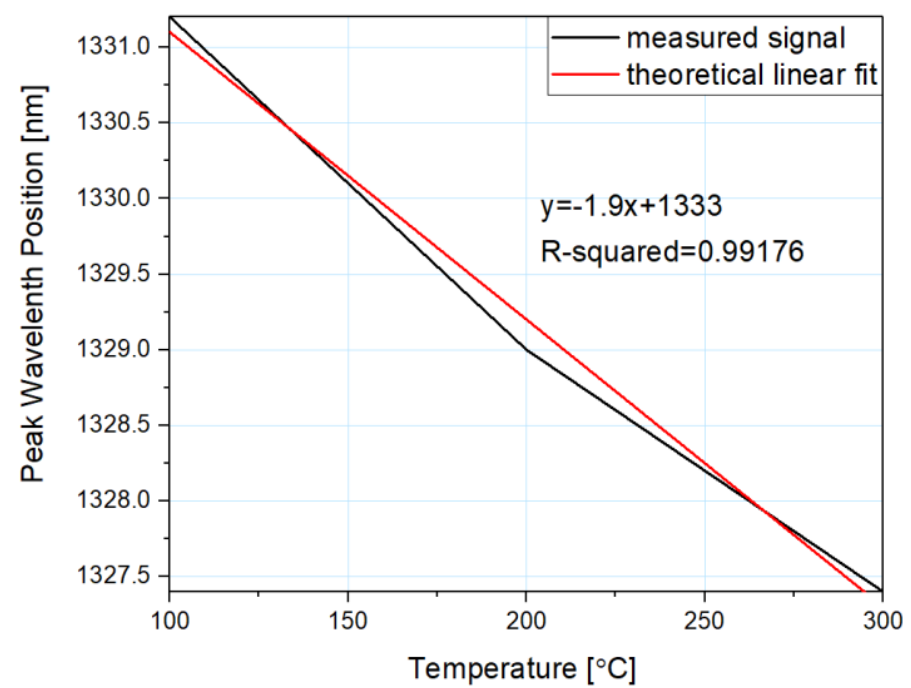

Figure 4. Dependence of the spectral shift of a reflected signal on the temperature.

The spectrum changes its peak wavelength position when the temperature is altered. The higher the temperature, the spectrum shift is constant throughout whole range of roughly $2 \mathrm{~nm}$ per $100^{\circ} \mathrm{C}$. By following linear regression, it is possible to determine the position of the reflected signal peak for each measured temperature. 


\section{Conclusion}

Microsphere-based sensors are ideal for long-term and remote measurements of parameters such as temperature or refractive index due to their ability to constantly monitor the integrity of the sensor head. Presented study a $100 \mathrm{~nm}$ ZnO ALD coating on the surface of a microsphere-based fiberoptic sensor for temperature measurements. Selection of an optimal coating is crucial for long-term and remote measurements. While devising the measurements, it is important to select proper parameters of the fiber-optic sensor coating for optimal efficiency. Sensor with a $100 \mathrm{~nm}$ ZnO ALD coating exhibits close match between measurement data and theoretical linear fit, which is confirmed by $R^{2}$ coefficient of over 0.99 . The sensitivity of the sensor with a $100 \mathrm{~nm}$ coating equals $0.019 \mathrm{~nm} /{ }^{\circ} \mathrm{C}$. Additionally, for microsphere-based sensor with $100 \mathrm{~nm}$ ZnO ALD coating, changes of temperature can be observed based on the spectral shift, which coincides with rise of the temperature. The sensor also indicates its proper operation by inciting interference.

Funding: This research was funded by the Polish National Agency for Academic Exchange-NAWA under bilateral exchange of scientists between France and Poland PHC Polonium (PPN/BFR/2019/1/00005). The author acknowledges the financial support of the DS Programs of the Faculty of Electronics, Telecommunications and Informatics of the Gdańsk University of Technology.

Conflicts of Interest: The authors declare no conflict of interest.

\section{References}

1. Xiong, F.B.; Sisler, D. Determination of low-level water content in ethanol by fiber-optic evanescent absorption sensor. Optics Communications 2010, 283, 1326-1330, doi:10.1016/j.optcom.2009.11.075.

2. Ramakrishnan, M.; Rajan, G.; Semenova, Y.; Farrell, G. Overview of Fiber Optic Sensor Technologies for Strain/Temperature Sensing Applications in Composite Materials. Sensors (Basel) 2016, 16, doi:10.3390/s16010099.

3. Karpienko, K.; Wróbel, M.S.; Jedrzejewska-Szczerska, M. Determination of refractive index dispersion using fiber-optic low-coherence Fabry-Perot interferometer: implementation and validation. Opt. Eng 2014, 53, 077103, doi:10.1117/1.OE.53.7.077103.

4. Witt, J.; Narbonneau, F.; Schukar, M.; Krebber, K.; De Jonckheere, J.; Jeanne, M.; Kinet, D.; Paquet, B.; Depre, A.; D’Angelo, L.T.; et al. Medical Textiles With Embedded Fiber Optic Sensors for Monitoring of Respiratory Movement. IEEE Sensors J. 2012, 12, 246-254, doi:10.1109/JSEN.2011.2158416.

5. Arif, Md.F.H.; Ahmed, K.; Asaduzzaman, S.; Azad, Md.A.K. Design and optimization of photonic crystal fiber for liquid sensing applications. Photonic Sens 2016, 6, 279-288, doi:10.1007/s13320-016-0323-y.

6. Van Newkirk, A.; Antonio-Lopez, E.; Salceda-Delgado, G.; Amezcua-Correa, R.; Schülzgen, A. Optimization of multicore fiber for high-temperature sensing. Opt. Lett. 2014, 39, 4812, doi:10.1364/OL.39.004812.

7. Wierzba, P.; Jędrzejewska-Szczerska, M. Optimization of a Fabry-Perot Sensing Interferometer Design for an Optical Fiber Sensor of Hematocrit Level. Acta Physica Polonica A 2013, 124, 586588, doi:10.12693/APhysPolA.124.586.

8. Wang, Q.; Wei, W.; Guo, M.; Zhao, Y. Optimization of cascaded fiber tapered Mach-Zehnder interferometer and refractive index sensing technology. Sensors and Actuators B: Chemical 2016, 222, 159-165, doi:10.1016/j.snb.2015.07.098. 
9. Azad, S.; Sadeghi, E.; Parvizi, R.; Mazaheri, A.; Yousefi, M. Sensitivity optimization of ZnO cladmodified optical fiber humidity sensor by means of tuning the optical fiber waist diameter. Optics $\mathcal{E}$ Laser Technology 2017, 90, 96-101, doi:10.1016/j.optlastec.2016.11.005.

10. Mishra, A.K.; Mishra, S.K.; Gupta, B.D. SPR based fiber optic sensor for refractive index sensing with enhanced detection accuracy and figure of merit in visible region. Optics Communications 2015, 344, 86-91, doi:10.1016/j.optcom.2015.01.043.

11. Song, N.; Cai, W.; Song, J.; Jin, J.; Wu, C. Structure optimization of small-diameter polarizationmaintaining photonic crystal fiber for mini coil of spaceborne miniature fiber-optic gyroscope. Appl. Opt. 2015, 54, 9831, doi:10.1364/AO.54.009831.

12. Tu, M.H.; Sun, T.; Grattan, K.T.V. Optimization of gold-nanoparticle-based optical fibre surface plasmon resonance (SPR)-based sensors. Sensors and Actuators B: Chemical 2012, 164, 43-53, doi:10.1016/j.snb.2012.01.060.

13. Listewnik, P.; Hirsch, M.; Struk, P.; Weber, M.; Bechelany, M.; Jędrzejewska-Szczerska, M. Preparation and Characterization of Microsphere ZnO ALD Coating Dedicated for the FiberOptic Refractive Index Sensor. Nanomaterials 2019, 9, 306, doi:10.3390/nano9020306.

14. Hirsch, M.; Listewnik, P.; Struk, P.; Weber, M.; Bechelany, M.; Szczerska, M. ZnO coated fiber optic microsphere sensor for the enhanced refractive index sensing. Sensors and Actuators A: Physical 2019, 298, 111594, doi:10.1016/j.sna.2019.111594.

(C) 2020 by the authors. Submitted for possible open access publication under the terms and conditions of the Creative Commons Attribution (CC BY) license (http://creativecommons.org/licenses/by/4.0/). 